\title{
Establishing a Screening System of Indoor Air Pollutants Using MEMS Sensor to Create Internet of Things Sensing Platform
}

\author{
Rina Yadav, ${ }^{1}$ Cheng-Chen Chen, ${ }^{2 *}$ Chia-Yen Lee, ${ }^{3}$ and Nien-Tsu Chen ${ }^{4}$ \\ ${ }^{1}$ College of Design, National Taipei University of Technology, \\ 1, Sec. 3, Zhongxiao E. Rd., Taipei 10608, Taiwan (R.O.C.) \\ ${ }^{2}$ Department of Architecture, National Taipei University of Technology, \\ 1, Sec. 3, Zhongxiao E. Rd., Taipei 10608, Taiwan (R.O.C.) \\ ${ }^{3}$ Undergraduate Program in Advanced Materials, National Pingtung University of Science and Technology, \\ 1, Shuefu Road, Neipu, Pingtung 912301, Taiwan (R.O.C.) \\ ${ }^{4}$ Department of Interior Design, Tung Fang Design University, \\ No. 110, Dongfang Rd., Hunei Dist, Kaohsiung 82941, Taiwan (R.O.C.) \\ (Received December 29, 2020; accepted May 11, 2021)
}

Keywords: indoor air quality, MEMS sensor, Internet of Things for information modeling, building materials

Recently, research has established a screening system comprising a combination of two technologies, the MEMS sensor and the field and laboratory emission cell (FLEC), to perform experiments. The aim of our study was to establish MEMS sensor field emission cell technology (MS-FECT) to measure the changes in the pollutant concentration of field emission cells. A building material emission database was created via an Internet of Things (IoT) in order to develop a MEMS sensor field emission modeling platform. On the basis of information of the building material emission database and decay models, the MS-FECT, IoT, indoor positioning system (Beacon), and cloud database are integrated in this system. The source of pollution was determined by sensing and data analysis to create a multidimensional map of pollution sources to determine air quality in order to monitor the location of pollutants and flow conditions in the long term to change the indoor air quality efficiently. Moreover, the results of this study will be helpful in house interior design, the maintenance of residents' health, and the reduction of carcinogenic threats.

\section{Introduction}

In recent years, European Union (EU) countries have suffered grave health and monetary problems triggered by indoor air pollution. A lot of money has been spent on air purification research to discover smart sensing devices. Since 2000, the EU has focused on smart sensing networks (e.g., IAQ Sense, EU NetAir), air health risk management, and the UNICEF Clear the Air for Children project. Regulations of the European Union Common Standard (CEN/TS 16516) and European Union Building Materials are used in the evaluation of the measurement of emissions into indoor air, and the use of certified low-emission building material products has been recommended. ${ }^{(1-4)}$ In 2014, the EU countries Germany and France incorporated the

*Corresponding author: e-mail: coolhas2000@yahoo.com.tw https://doi.org/10.18494/SAM.2021.3273 
Verification of Low-Emission Building Materials law into the legal system for enactment. Belgium and the United Kingdom announced the implementation of similar laws in 2015.

Formaldehyde and phthalate acid esters (PAEs) are often used in speed-increasing agents; many documents have also proved their toxicity, which is expected to cause health problems. The research of the escape state of different benzenes and the assessment results of the health risks at different temperatures have been used to construct a passive sampling device for plastic materials such as synthetic leather, wallpaper, and ethylene flooring. The observed maximum emissions of diethylphthalate, dibutylphthalate, and diethylhexylphthalate (DEHP) were observed to be $0.89,0.77$, and $14 \mu \mathrm{g} / \mathrm{m}^{2} / \mathrm{h}$ at $20{ }^{\circ} \mathrm{C}$ and $2.8,450$, and $1500 \mu \mathrm{g} / \mathrm{m}^{2} / \mathrm{h}$ at $80{ }^{\circ} \mathrm{C}$, respectively. ${ }^{(5)}$ The field and laboratory emission cell (FLEC) method was used to study the effects of RH on volatile organic compounds (VOCs). In 2007, childhood asthma was found to often occur in damp and phthalate-emitting buildings. ${ }^{(6)}$ The FLEC method has been used to discuss the relationship between humidity and the concentration of phthalates. Ethylene flooring containing $17 \%(\mathrm{w} / \mathrm{w})$ DEHP was placed in six test FLECs at $22{ }^{\circ} \mathrm{C}$, and it was observed that the specific emission rate (SER) of DEHP from vinyl flooring (VF) over one year was independent of RH. ${ }^{(7)}$

To study the emission of VOCs from building materials, an advanced diffusive sampling emission cell (ADSEC) detection method was published by Matsumoto et al. in 2002, ${ }^{(8)}$ and this detection method is used to detect $\mathrm{VOCs}^{(9)}$ of building materials on site. Toluene, styrene, and xylene were the most common VOCs. The effect of common building materials and some emitted pollutants such as total volatile organic compounds (TVOC) has been studied, and the correlation between air quality and wellbeing was established. ${ }^{(10)}$ The sandwich environment control cabin method of detecting VOCs from building materials was proposed by $\mathrm{Xu}$ et al. in 2012, and they conducted emission tests. The concentration of DEHP that escaped from the VF of a unique stainless steel microcabin designed in the laboratory was measured. In the steel microcabin, the DEHP concentration in the gaseous phase slowly increased, reaching a steadystate level of $0.8-0.9 \mu \mathrm{g} / \mathrm{m}^{3}$ after 20 days. With increasing surface area of the ethylene floor and decreasing thickness of the stainless steel surface, the time to reach a steady state was shortened. ${ }^{(11)}$

Adsorption and desorption by indoor surface materials have significant effects on the level of indoor VOCs. The surface sink model (SSM) was developed and studied to interpret these effects in an indoor air quality (IAQ) model. ${ }^{(12)}$ Three-dimensional computational fluid dynamics (3D-CFD) analysis of diffusion and emission of VOCs has been done by Zhu et al. in a FLEC cavity with a total flow of $250 \mathrm{ml} / \mathrm{min}^{(13)}$ Indoor air pollution was also detected using a tin oxide gas sensor in 1995. ${ }^{(14)}$ Combustible gas (CG), ammonia (AM), carbon monoxide (CO), carbon dioxide $\left(\mathrm{CO}_{2}\right)$, nitrogen oxide (NX), absolute humidity $(\mathrm{AH}), \mathrm{RH}$, and temperature (TM) sensors were used to study indoor air pollution. These sensors were linked to a microcomputer via an $\mathrm{A}-\mathrm{D}$ converter. Cigarette smoke, $\mathrm{CO}_{2}$ gas, $\mathrm{CO}$ gas, ethanol gas, and commercial propane were measured as a function of time. The $\mathrm{CG}$ and $\mathrm{AM}$ sensors were sensitive to all pollutants in gaseous form, except for $\mathrm{CO}_{2}$ gas. ${ }^{(15)}$

Indoor air pollution is one of the top environmental threats to public health. IAQ has a significant impact on people's health. Two problems have been identified regarding IAQ: short- 
term monitoring bias and IAQ data-monitoring challenges. These can be solved by Internet of Things (IoT) and distributed ledger technologies (DLTs). ${ }^{(16)}$ Emissions of VOCs and formaldehyde from indoor building materials have long been studied. ${ }^{(17)}$ Studies of the evaluation of the adsorption performance of green building materials by the source control method to control the indoor air quality ${ }^{(18,19)}$ and the use of a smart sensor to detect the pollution concentration in air and their application to building environments and the IoT field are recent trends. In 2018, we published a study in which we employed MEMS sensor field emission cell technology (MS-FECT) to test passive adaption building materials and smart air sensing technology to monitor the concentration of formaldehyde. The eye blinking frequency was found to increase with the amount of formaldehyde in the air. This experiment was helpful for the detection of indoor formaldehyde sources. ${ }^{(20)}$ In another study, we analyzed the relationship between contamination resources and the removability of contamination using an IoT connecting system and full-scale space. ${ }^{(21)}$

\section{Materials and Methods}

The following are the main purposes of this project: establish a locally applicable on-site screening technology for emission pollutants from indoor building materials; establish a database of on-site emission test tanks for building materials; establish a comparative analysis method using smart microsensing technology, and integrate smart technology and building material detection technology.

The VOC emission and mass balance theory of building materials is based on Fick's second law and the mass balance chamber model [Eq. (1)], where $y(t)$ is the gas-phase compound concentration in the chamber, $t$ is time, $D$ is the material-phase diffusion coefficient, $A$ is the exposed surface area of the source, $C(x, t)$ is the material-phase compound concentration at position $x$ and time $t, x$ is the distance from the base of the slab-shaped material, $L$ is the thickness of the material, and $Q$ is the air flow rate through the chamber. In the VOC estimation model for building material emissions, VOCs are quantified into gas phase concentrations on the basis of the diffusion method of solid building materials. ${ }^{(22)}$ The mass transfer process and boundary distribution of the VOCs in a cabin have a strong relationship with the concentration of VOCs in air and time. When the VOC gas moves to the walls of the environmental control cabin, it will adsorb onto or absorb into the surface material. When the temperature rises or the airflow increases, the VOC gas will desorb from the surface material and escape into the indoor air. The escape mode is described below (Fig. 1).

$$
V \frac{d y(t)}{d t}=-\left.D \cdot A \frac{\partial C(x, t)}{\partial x}\right|_{x=L}-Q \cdot y(t)
$$

Our research has focused on a microsensing chip fabricated by a MEMS semiconductor manufacturing process (Fig. 2) and long-term sensor issues such as miniaturization and noninterference. In our previous research in 2016, we determined the emission of formaldehyde 


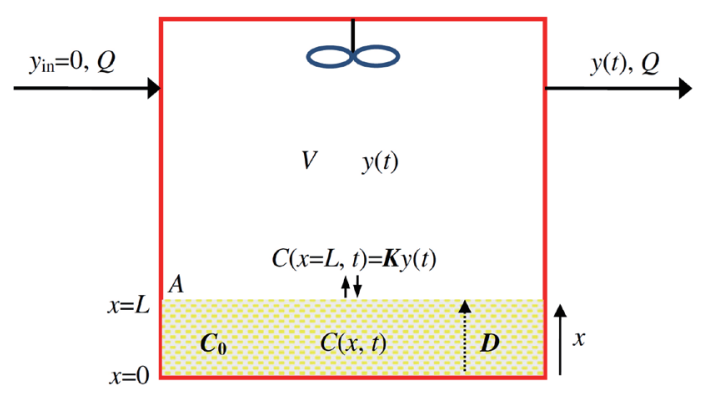

Fig. 1. (Color online) VOC emission chamber model (Liu et al., 2013). (20)

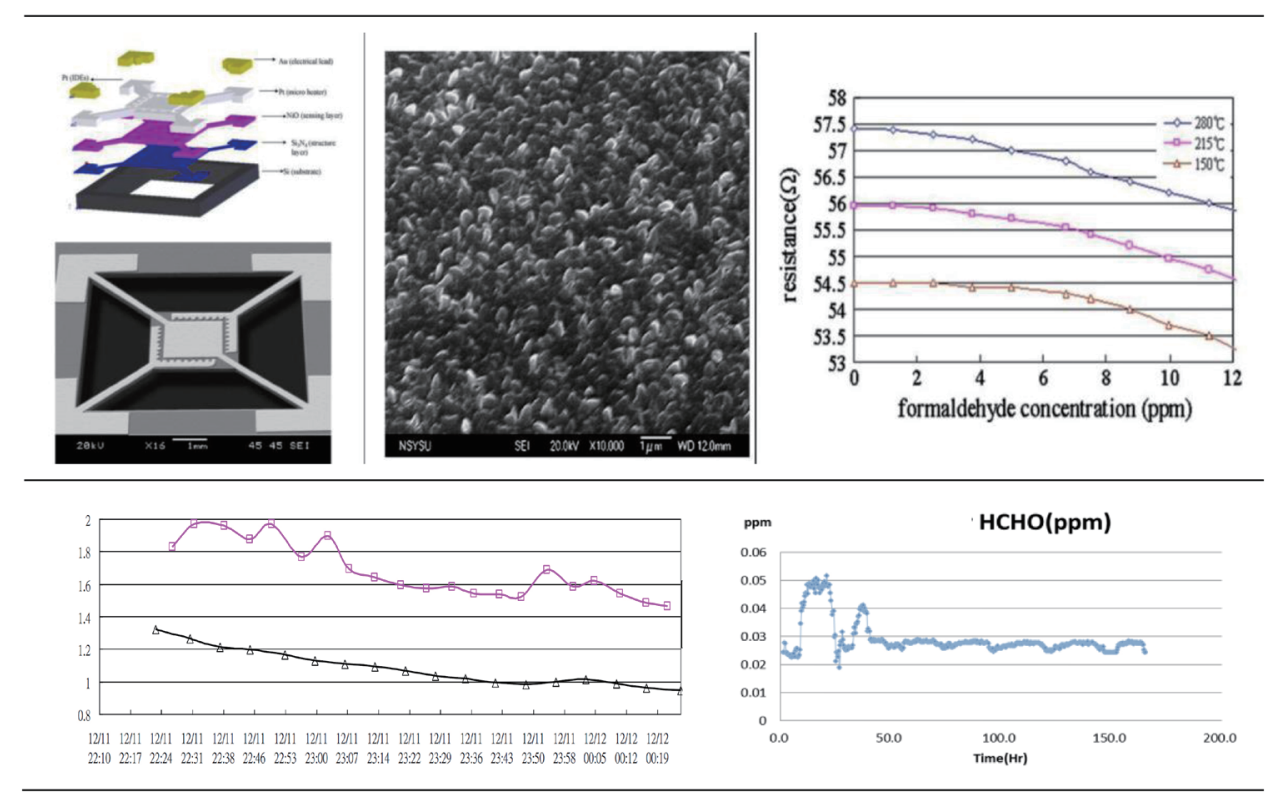

Fig. 2. (Color online) Details of microsensing chip for detecting formaldehyde gas emitted from building materials. (Source: Project cohost, Professor Chia-Yen Lee, National Pingtung University of Science and Technology, 2013) (MOST-103-2221-E-272-003-) (Lee et al., 2006). (21)

from building materials and furnishings. ${ }^{(21)}$ The emission test cell method was used in an innovative combination. On-site screening technology of emissions from building materials in a room (MS-FECT) and the use of smart microsensing chips to detect pollution in building materials in a field emission test chamber were established. Changes in the concentrations of substances were measured using the developed MS-FECT and general laboratory testing methods (Fig. 3, Table 1). The small environmental control box test method was compared with another reported method and its validity was verified; the results showed that the coefficient of variation (C.V.) between the two methods was $18.78 \%$, which was within a reasonable range. ${ }^{(22)}$

An IoT information modeling platform is investigated using ICT data recording and transmission technology, combined with the building material escape-rate database (building material emission database) and emission models (emission model, emission and decay model, 


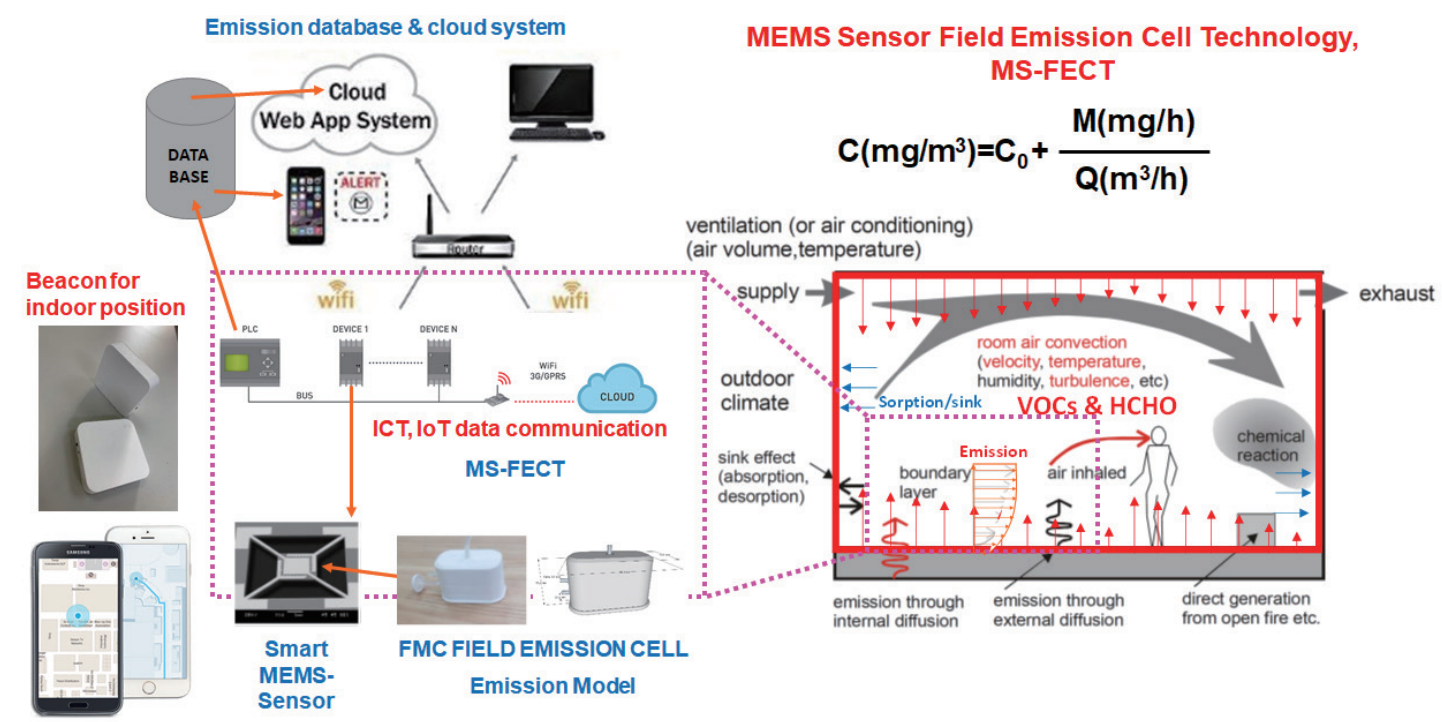

Fig. 3. (Color online) Concept of smart sensing and building material field emission test slot (MS-FECT) in fullscale space. ${ }^{(23)}$

Table 1

Screening system for pollutants emitted from indoor building materials using smart microsensing technology. (Liu et al., 2018) ${ }^{(22)}$

\begin{tabular}{llc}
\hline Smart sensing and building material field emission test slot (MS-FECT) \\
\cline { 2 - 3 }
\end{tabular}

mass transfer model, exponential diffusion model, etc.) and other basic information. The on-site screening technology of pollutants emitted from indoor building materials is connected with the IoT, an indoor positioning system, a building information modeling (BIM) system, and an integrated cloud database to realize smart microsensing and data analysis.

To determine whether building materials are the sources of pollution, a three-dimensional map of IAQ and building material pollution sources was established to monitor indoor pollution over a long time. The distribution and flow of objects can effectively and accurately improve IAQ, which is helpful for the design, transformation, and maintenance of a building's indoor space. 
In this study, we use the Beacon system, in which the IoT, indoor positioning technology (indoor positioning system), an information modeling system, and a cloud database are integrated (Fig. 4).

\section{Results and Discussion}

In this research, we use smart microsensing chips to sense changes in the concentration of pollutants. On-site screening technology, the IoT indoor positioning system, the information model system, and the cloud database were integrated to construct the IoT information model platform for smart microsensing (Fig. 5) of indoor building materials. With on-site sensing and the analysis of data obtained through real-time screening to determine which indoor building materials are the sources of pollution, we can also establish an IAQ information platform. The future integration of a multipoint positioning system can enable the production of an IAQ multidimensional map, which can be used to monitor IAQ.

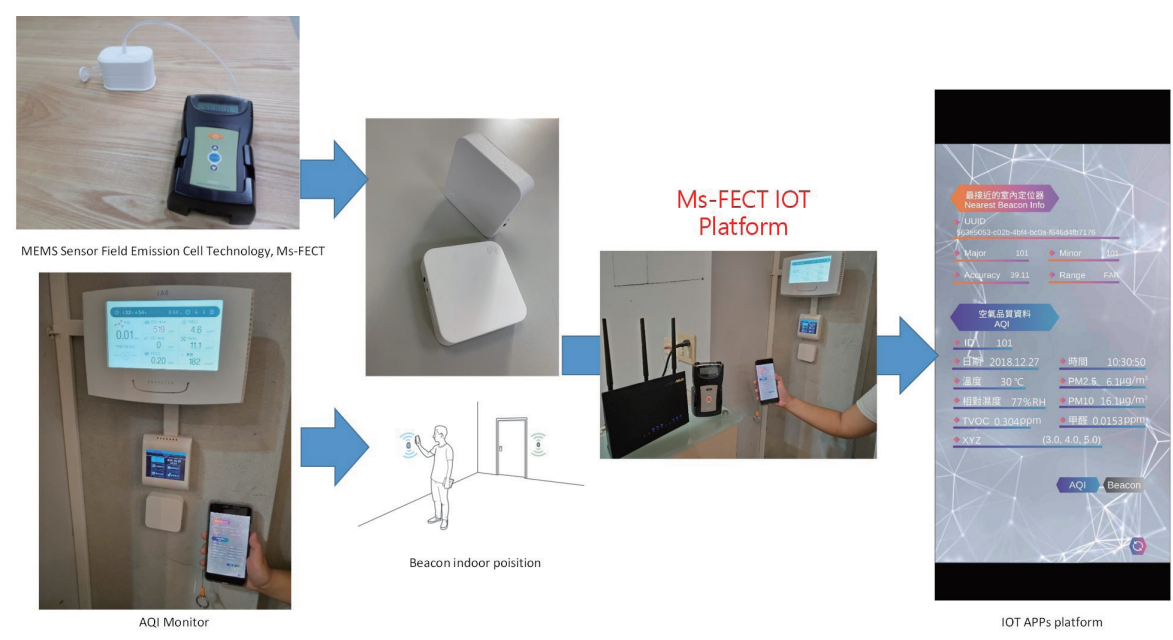

Fig. 4. (Color online) MS-FECT and cloud connected via Beacon system and IoT.

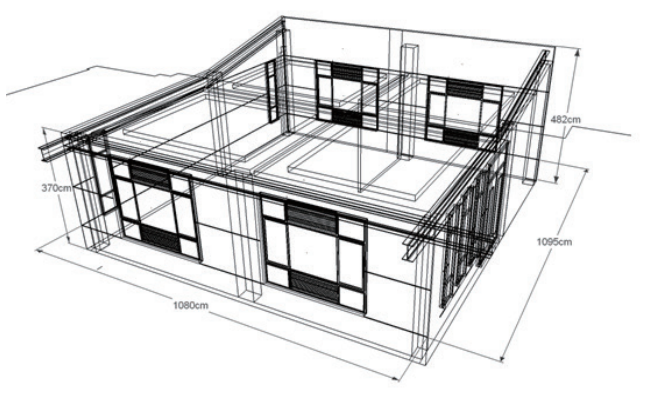

(a)

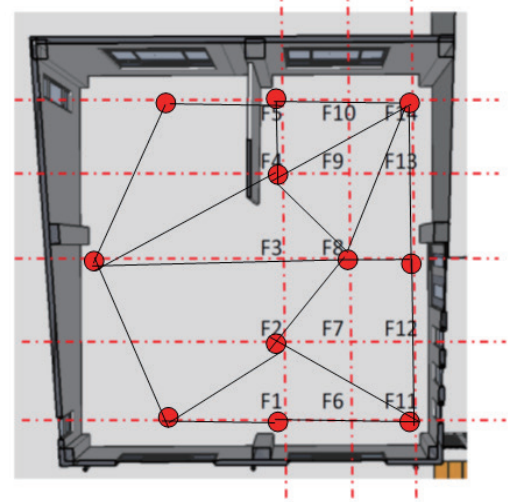

(b)

Fig. 5. (Color online) Smart microsensing chip data integrated into an IoT information model platform: (a) fullscale test lab and (b) optimized mesh grid of IAQ monitoring position. 


\subsection{Experiments to test IoT information model platform for smart microsensing screening of pollutants emitted by indoor building materials}

In this research, multiple sets of experiments were conducted on the IoT information model platform for the smart microsensing screening of emissions from indoor building materials (Fig. 6). Separate studies were conducted on the indoor air pollutants emitted by building materials (short-term experiment) and on experiments of monitoring indoor air (long-term experiment).

We use smart microsensing chips to sense changes in the concentration of pollutants and study the ICT data recording and transmission technology in combination with the on-site screening technology of the pollutants emitted from indoor building materials with the IoT. Data on sensor position and emitted pollutants were acquired in a single room space to establish a pollutant database through long-term continuous measurement. To establish this database, five types of flooring data and nine types of indoor air pollutants were used. Positioning data were immediately transmitted to the MEMS sensing instrument via Bluetooth to monitor IAQ. Also, through the cloud connection of Beacon and web apps, data were integrated into the IoT information platform using various mobile phones and computers. In the future, the information model can be extended to entire-building recognition, and the use of the building space can save labor costs and shorten the operation time.

\subsection{Evaluation of the expansion of IoT information model platform}

The integration of on-site screening technology for pollutants emitted from indoor building materials into the IoT information model platform is currently classified as building material

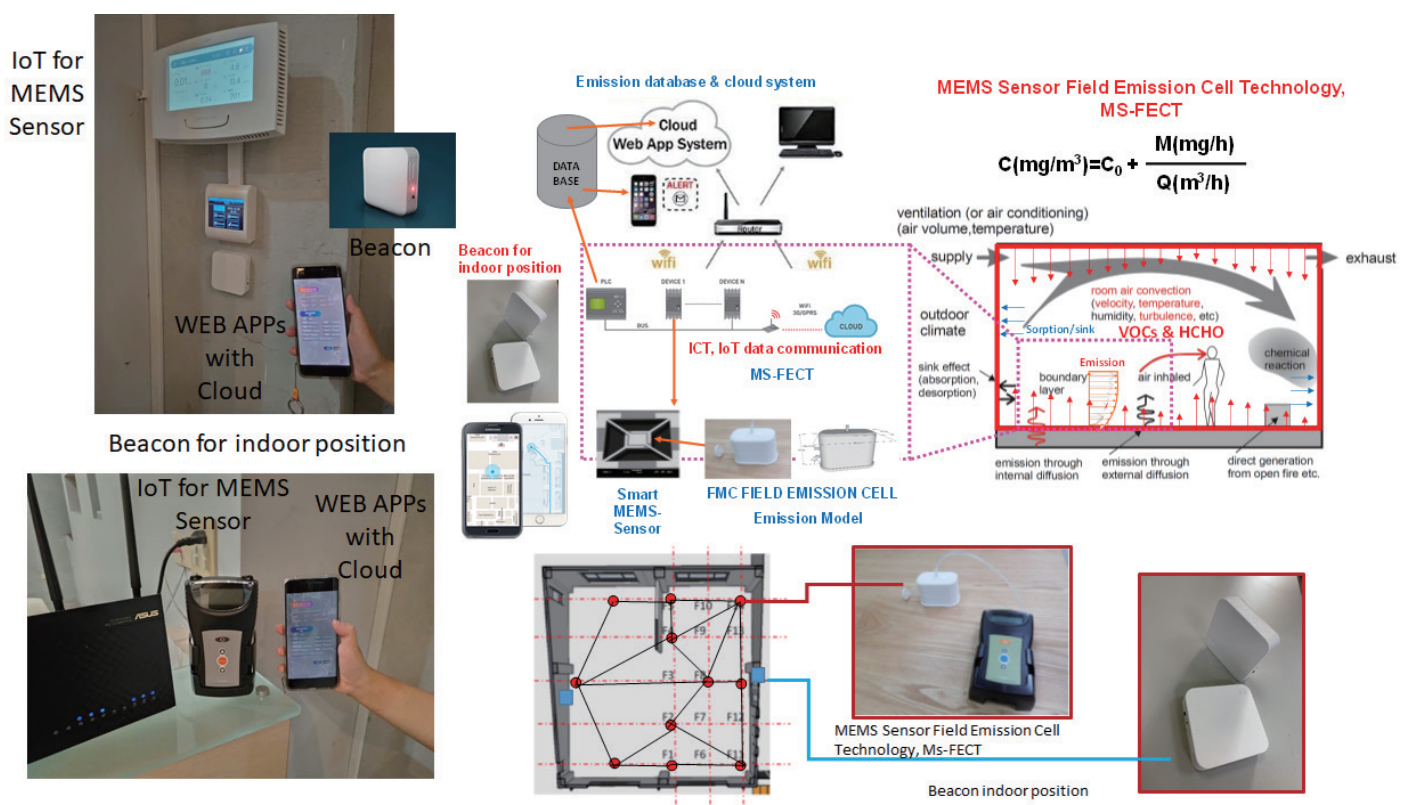

Fig. 6. (Color online) Experiment on IoT information model platform for smart microsensor screening of pollutants emitted by indoor building materials. 
detection (pollution source screening) and continuous monitoring of air pollutants (air quality monitoring) on the basis of measurement factors. Nine environmental factors corresponding to platform data are used: temperature, humidity, the amounts of $\mathrm{CO}_{2}, \mathrm{CO}, \mathrm{TVOC}$, formaldehyde, PM2.5, and PM10, and fungal tendency. The potential index, corresponding to the MS-FECT, is equivalent to that of formaldehyde and TVOC. In the future expansion of the platform, test items of building materials can be added, and indoor air can be used to identify the source material of pollution and to control the concentrations of indoor air pollutants in order to maintain IAQ.

This work is an extension of our 2016 research on building a screening system for pollutants emitted from indoor building materials using smart microsensing technology (No. 1 annual plan), smart microsensing MEMS sensors, and the chamber method of determining room internal air emissions of VOCs from building materials and furnishings used in the establishment of an indoor environment. An IAQ map of building material pollution sources can also be established to monitor the distribution and flow of indoor pollutants over a long time, to effectively and accurately improve IAQ, to aid the design and transformation of building indoor spaces, and to reduce the risk of cancer to maintain the health and comfort of occupants.

We built an IoT information model platform for the smart microsensing detection of pollutants emitted from indoor building materials. To reduce health hazards and risks to personnel, new testing items such as the emission of VOCs from building materials are controlled by environmental on-site real-time screening and evaluation methods.

The following three steps are involved in the evaluation of the IoT information model platform.

(1) Establish an on-site screening technology for pollutants emitted from indoor building materials (MS-FECT)

3D information values of building IAQ (IAQ-BIM data) were obtained using an innovative combination of MEMS sensors and the building material field and experimental emission test slot method (FLEC). First of all, the indoor building material inspection technology (MS-FECT) was developed using a smart microsensing chip (Fig. 7) to sense changes in the concentrations of pollutants. Data were obtained under different experimental conditions in order to establish an escape-rate database.

(2) Construct a smart microsensing screening system for pollutants emitted from indoor building materials

Then, the on-site screening technology was combined with the IoT, an indoor positioning system, and a BIM integrated cloud database to create a smart microsensor model IoT platform. Data obtained through this developed platform were used to analyze the source of pollution.

(3) Construct an IAQ cloud system for the smart microsensing screening system for pollutants emitted from indoor building materials

The microsensing screening system for pollutants emitted from indoor building materials uses ICT wireless transmission technology to integrate data. However, in the indoor part, it is assisted by the Beacon indoor positioning system to accurately locate the indoor building material pollutants and obtain escape data of the pollutants. Together with the information modeling system, the system can be applied in the future to establish a 3D map of building material pollution sources. 

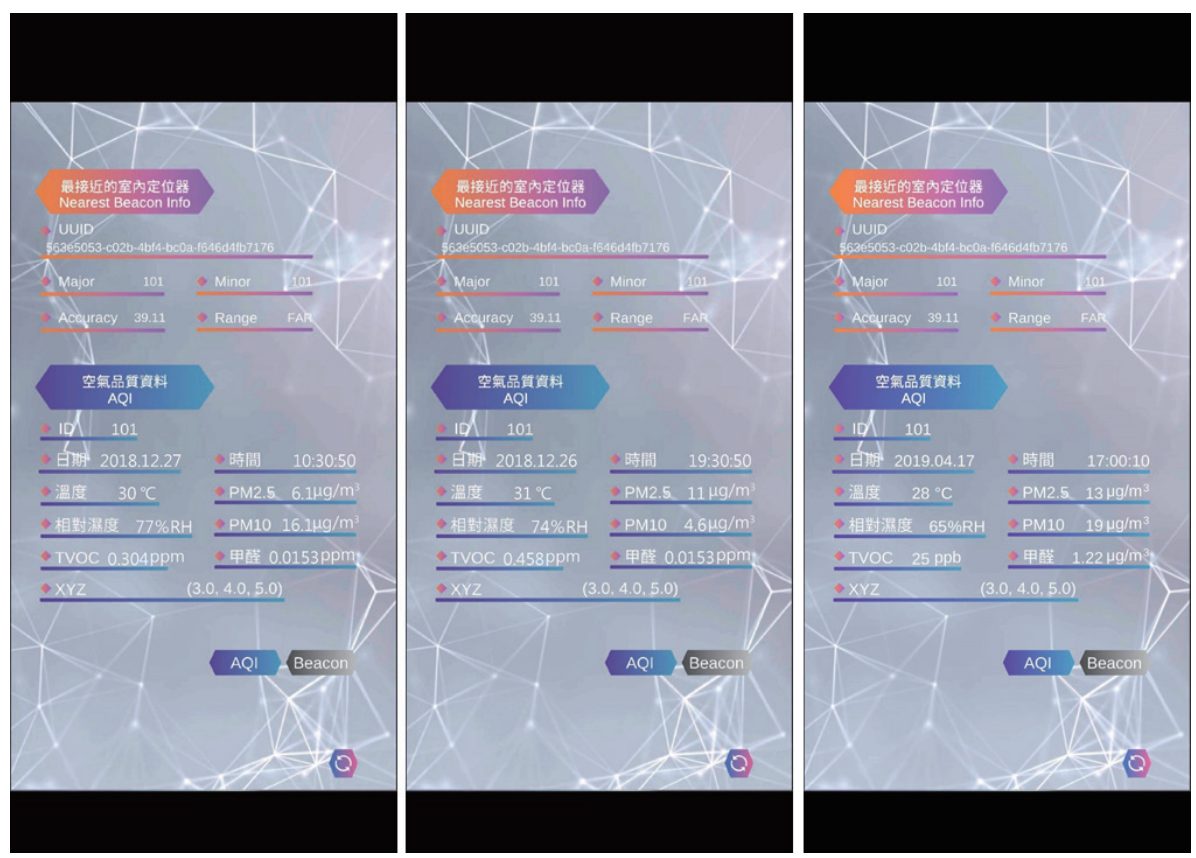

Fig. 7. (Color online) MEMS sensor to create sensing IoT platform.

\section{Conclusions and Suggestions}

It is essential to identify and control the source of indoor pollutants and the air quality to maintain the health and comfort of the occupants. The results of this research will aid the reduction of pollution sources in existing buildings and the design of new buildings. The integration of information enables the rapid detection and management of relevant air pollutant data, thereby reducing the required labor and the burden of managing material resources and data reporting. It is also helpful in maintaining the health and comfort of occupants and expanding the development of industrial technology.

The innovative combination of MEMS sensors and the building materials field and the experimental emission test slot method (FLEC) is applied to sense pollution using smart microsensing chips. The change in the concentration of materials leads to the need to detect indoor building material pollution sources. This was achieved by connecting the smart microsensing indoor building materials and the IoT information model platform to reduce indoor air pollution. The application of IAQ management and healthy green building materials helped to establish a building information system incorporating Beacon. Data push and data integration resulted in a cloud data platform for a digital information model comprising various operating systems controlled via mobile phones and computers for building management applications and the control of indoor air pollution.

However, data push and management in complex multilayered spaces have not yet been verified owing to a lack of time and labor. Artificial intelligence (AI) calculation methods can be introduced in the future to improve calculation feasibility. The uncertainty of the measurement 
will continue to be examined in the follow-up research to ensure that the reliability and validity of the measurement meet the requirements specific to the application. The stability, calibration, and detection limit of the test chip should be continuously studied and refined. The indoor positioning system can be created with Beacon, using Bluetooth to communicate with the BIM information system. In the foreseeable future, the results of this research can be applied to actual architectural space installations to understand their empirical performance and promote related dynamic innovative technologies in industrial research and development.

\section{Acknowledgments}

This research was supported by the Ministry of Science and Technology (MOST-1072221-E-272-001- and MOST-105-2221-E-272-002-) and Professor Kuang-Sheng Liu of the Department of Interior Design, Tung Fang Design University, who provided the equipment and laboratory space.

\section{References}

1 ISO-16000-10 Indoor air -Part 10: Determination of the emission of volatile organic compounds from building products and furnishing-Emission Test Cell, 2006: https://www.iso.org/standard/38204.html (accessed October 2020).

2 BS ISO-16000-3:2011- Indoor air: Determination of formaldehyde and other carbonyl compounds -Active sampling method: https://www.iso.org/standard/51812.html (accessed October 2020).

3 BS ISO-16000-4:2011- Indoor air-Determination of formaldehyde -Diffusive sampling method: https://www. iso.org/standard/52214.html (accessed September 2020).

4 ISO-16000-6 Indoor air -Part 6: Determination of volatile organic compounds in indoor and test chamber air by active sampling on Tenax TA sorbent, thermal desorption and gas chromatography using MS-FID, 2004: https://www.iso.org/standard/52213.html (accessed September 2020).

5 M. Fujii, N. Shinohara, A. Lim, T. Otake, K. Kumagai, and Y. Yanagisawa: Atmos. Environ. 37 (2003) 5495. https://doi.org/10.1016/j.atmosenv.2003.09.026

6 J. J. Jaakkola and T. L. Knight: Environ Health Perspect. 116 (2008) 845. https://doi.org/10.1289/ehp.10846

7 Y. Xu, V. Kofoed-Sørensen, J. C. Little, and P. Wolkoff: Atmos. Environ. 41 (2006) 3217. https://doi. org/10.1016/j.atmosenv.2006.06.063

8 J. Matsumoto, S. Tanabe, and R. Aoki: Indoor Air (2002). https://www.irbnet.de/daten/iconda/CIB6301.pdf

9 B. C. Singer, K. L. Revzan, T. Hotchi, A. T. Hodgson, and N. J. Brown: Atmos. Environ. 38 (2004) 2483. https://doi.org/10.1016/j.atmosenv.2004.02.003

10 M. Bucakova and I. Senitkova: Proc. CLIMA 2007 - Wellbeing Indoors (10-14 June Helsinki, 2007). https:// www.aivc.org/resource/building-material-interactions-and-perceived-air-quality

11 Y. Xu, Z. Liu, J. Park, P. A. Clausen, J. L. Benning, and J. C. Little: Environ. Sci. Technol. 46 (2012) 12534. https://doi.org/10.1021/es302319m

12 D. Won, D. M. Sander, C. Y. Shaw, and R. L. Corsi: Atmos. Environ. 35 (2001) 4479. https://doi.org/10.1016/ S1352-2310(01)00223-0

13 Q. Zhu, S. Kato, S. Murakami, and K. Ito: Indoor Air. 17 (2007) 178. https://doi.org/10.1111/j.16000668.2006.00453.X

14 T. Oyabu, H. Kimura, and S. Ishizaka: Sens. Mater. 7 (1995) 431. https://myukk.org/SM2017/article. php?ss=10219

15 T. Oyabu, S. Hirobayashi, and H. Kimura: Sens. Mater. 9 (1997) 177. https://myukk.org/SM2017/sm_pdf/ SM284.pdf

16 S. Sun, X. Zheng, J. Villalba-Díez, and J. Ordieres-Meré: Sensors 19 (2019) 4157. https://doi.org/10.3390/ $\underline{\text { s19194157 }}$

17 J. Xiong, C. Liu, and Y. Zhang: Atmos. Environ. 47 (2012) 288. https://doi.org/10.1016/j.atmosenv.2011.10.063

18 W. Sakr, C. J. Weschler, and P. O. Fanger: Indoor Air 16 (2006) 98. https://doi.org/10.1111/j.16000668.2005.00406.X 
19 D. Won, R. L. Corsi, and M. Rynes: Indoor Air 11 (2001) 246. https://doi.org/10.1034/j.1600-0668.2001.110406.x

20 Z. Liu, W. Ye, and J. C. Little: Build. Environ. 64 (2013). 0360. https://doi.org/10.1016/j.buildenv.2013.02.012

21 C. Y. Lee, C. H. Lin, P. C. Chou, L. M. Fu, P. R. Hsieh, and C. M. Chiang: J. Microsyst. Technol. 12 (2006) 893. https://doi.org/10.1007/s00542-006-0119-x

22 K. S. Liu and C. C. Chen: Civil Eng. Arch. Eng. 106 (2018) 53. https://doi.org/10.3966/101632122018120106004

23 C. C. Chen, L. H. Chen, and M. H. Guo: IEEA 19, Proc. Int. Conf. Informatics, Environment, Energy and Applications, March (2019) 15-20. https://dl.acm.org/doi/abs/10.1145/3323716.3323734

\section{About the Authors}

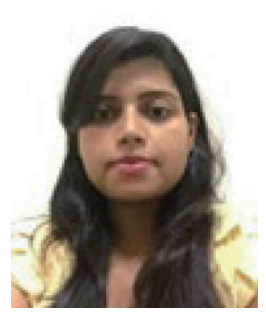

Rina Yadav received her B.Arch. degree from Integral University, Lucknow, India, in 2013 and her Master's degree from National Taiwan University of Science and Technology in 2016. She is currently pursuing her Ph.D. degree from National Taipei University of Technology. She worked as a part-time research assistant in 2017-2019. Her research interests are green materials, sustainability, energy efficiency and low carbon footprint, sensor materials, indoor air quality, and solutions that perform well from indoor and outdoor environmental, economic, and social viewpoints. (rina8jan@gmail.com)

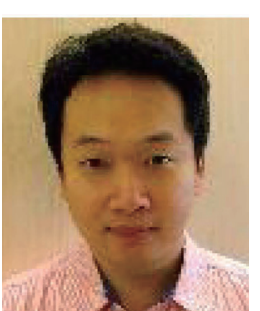

Cheng-Chen Chen received his $\mathrm{PhD}$ degree from National Cheng Kung University, Tainan, Taiwan, in 2012 and his Master's degree from Cheng Kung University in 2004. He was an assistant professor from 2013 to 2019 and is currently an associate professor. His research interests are the indoor environment, smart buildings, IoT and building materials, and optimality applied to indoor environmental, health, co-benefit, and social aspects. (coolhas2000@yahoo.com.tw)

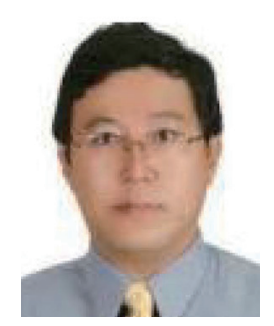

Chia-Yen Lee received his PhD degree from National Cheng Kung University, Tainan, Taiwan, in 2004 and his Master's degree from Taiwan University in 1993. He was a professor from 2010 to 2020 and served as vice dean of the College of Engineering from 2011 to 2019. His research interests are MEMS, IoT and macromolecular materials, and microsensors that perform well with respect to MEMS, bioengineering, and sensor technology.

(leecy@mail.npust.edu.tw)

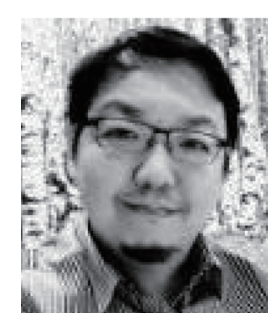

Nien-Tsu Chen received his $\mathrm{PhD}$ degree from National Cheng Kung University, Tainan, Taiwan, in 2007 and his Master's degree from Cheng Kung University in 2001. He was an associate professor from 2015 to 2020 and held the post of the chair of the Department of Interior Design from 2013 to 2020. His research interests are the indoor environment, CFD, IAQ and ventilation, and solutions that perform well with respect to indoor environmental, health, and social aspects. (elenick37@hotmail.com) 